\title{
Social phobia in Parkinson's disease: Prevalence and risk factors
}

This article was published in the following Dove Press journal:

Neuropsychiatric Disease and Treatment

21 May 2014

Number of times this article has been viewed

\author{
Bulent Kadri Gultekin' \\ Betul Ozdilek ${ }^{2}$ \\ Engin Emrem Bestepe' \\ 'Department of Psychiatry, \\ ${ }^{2}$ Department of Neurology, Erenkoy \\ Research and Training Hospital for \\ Neurologic and Psychiatric Disorders, \\ Istanbul, Turkey
}

Objective: We aimed to investigate the frequency of social phobia in patients with Parkinson's disease (PD). In addition, we explored the relationship between social phobia and the clinical characteristics of $\mathrm{PD}$, and the frequency of comorbid psychiatric disorders in PD patients.

Methods: This study included 80 consecutive patients with PD admitted to the Parkinson's disease and Movement Disorders Clinic at the Erenkoy Research and Training Hospital for Neurologic and Psychiatric Disorders, Istanbul, Turkey and used demographic and clinical data. The PD patients were evaluated during the "on state", using the Hoehn and Yahr scale, the Unified Parkinson's Disease Rating Scale, and the Schwab England Activities of Daily Living Scale. Psychiatric evaluations were conducted using the Diagnostic and Statistical Manual of Mental Disorders, Fourth Edition structured clinical interview, the Liebowitz Social Anxiety Scale (LSAS), and the Hamilton Depression Rating Scale.

Results: Social phobia was diagnosed in $42.5 \%$ of PD patients. Social phobia was comorbid with depression in 20 patients $(58.8 \%)$, generalized anxiety disorder in 18 patients $(52.9 \%)$, and panic disorder in six patients $(17.6 \%)$. Social phobia was more frequent in males, early-onset $\mathrm{PD}$, patients with a long duration of disease, the presence of postural instability, and with the use of a high Levodopa equivalent daily dose. A logistic regression analysis revealed the predictive factors of social phobia to be the sex of the patient (more frequent in males) and the presence of postural instability. There was a statistically significantly negative correlation between the LSAS score and the age of disease onset $(r=-0.503 ; P=0.002)$ and a positive correlation between LSAS score and the duration of disease $(r=0.374 ; P=0.023)$.

Conclusion: Social phobia is frequently observed in PD patients. Therefore, the assessment of PD patients should always include psychiatric evaluations, particularly for social phobia. The early detection and treatment of social phobia in PD patients is very important for the quality of life of patients as well as caregivers.

Keywords: Parkinson's disease, social phobia, psychiatric disorders

\section{Introduction}

The incidence of anxiety in patients with Parkinson's disease (PD) has recently begun to draw attention as it has been reported that $40 \%$ of PD patients experience clinically significant anxiety. ${ }^{1}$ This anxiety may be a psychological reaction to the stress of the disease, it may be related to the neurochemical changes caused by the disease itself, or it may be caused by the drugs used to treat PD. These anxiety disorders primarily manifest as panic disorder, phobic disorder, or generalized anxiety disorder. ${ }^{1}$ A Turkish study by Tunc et al found an elevation of anxiety-like behaviors in 50 PD patients compared with controls, as well as a significant correlation between the severity of PD and levels of anxiety. ${ }^{2}$ 
Social phobia is characterized by constant fear of embarrassment and humiliation in social situations, in which an individual feels as if he/she is being observed by others. According to the Diagnostic and Statistical Manual of Mental Disorders, Fourth Edition (DSM-IV), people with social phobia avoid fear-evoking social situations or participate in them with intense anxiety. ${ }^{3}$ Because the motor symptoms of PD, such as bradykinesia, rigidity, and tremors, can be noticed by others, this population can be considered a highrisk group for the development of social phobia. However, few studies have investigated the incidence of social phobia in PD patients. According to the DSM-IV, the diagnosis of social phobia or any other psychiatric disorder is contingent on whether there is a general medical condition present in an individual, in which case the diagnosis of "Anxiety Disorder not otherwise specified" is attached to social phobic symptoms associated with physical problems. ${ }^{3}$ This requirement of a nonspecific diagnosis has resulted in social phobia being a relatively less studied issue when comorbid with a general medical condition, although a number of studies have reported that medical diseases often result in social phobia. For example, Topçuoğlu et $\mathrm{al}^{4}$ found that $42.2 \%$ of people with essential tremor have social phobia. Stein et $\mathrm{al}^{5}$ observed social phobia in seven of 16 stutter patients (43.7\%) and Gündel et $\mathrm{al}^{6}$ diagnosed social phobia in $41.3 \%$ of 116 spasmodic torticollis patients.

To date, few studies have investigated the prevalence and risk factors of social phobia in PD patients, and only a single Turkish study has looked at the frequency of social anxiety in this population. ${ }^{2}$ Thus, we investigated the frequency of social phobia and other psychiatric disorders in PD patients.

\section{Methods}

\section{Sampling}

The present study was a cross-sectional investigation of 84 consecutive PD patients who presented at the Parkinson's Disease and Movement Disorder Clinic at the Erenkoy Research and Training Hospital for Neurologic and Psychiatric Disorders, Istanbul, Turkey, between March and August of 2013. Four people who did not agree to participate in the study were excluded from the final analyses. Local ethics committee approval and written informed consent were obtained from all patients for this study.

\section{Instruments}

\section{Sociodemographic data form}

The following sociodemographic data were obtained for all patients: age, sex, total years of education, work and marital status, monthly income, and whether they had health insurance. Clinical information related to PD, such as the clinical phenotype of PD (tremor-dominant or bradykinesia-dominant), the laterality of symptoms (right or left), the presence of postural instability, disease duration (years), and levodopa equivalent daily dose (LEDD) were also recorded.

\section{DSM-IV Structured Clinical Interview}

Psychiatric evaluations were performed using the Structured Clinical Interview for DSM-IV Axis I Disorders (SCID-I). The reliability and validity of this interview for the purposes of this study were initially determined by First et $\mathrm{al}^{7}$ and subsequently for the Turkish language by Ozkurkcugil et al. ${ }^{8}$

\section{Liebowitz Social Anxiety Scale}

The Liebowitz Social Anxiety Scale (LSAS) was developed to evaluate avoidance behaviors and/or fear in social relationships and anxiety during social situations. ${ }^{9}$ This scale consists of 24 items and is composed of two subscales measuring one's social relationship (eleven items) and social performance (13 items). The items were scored by a trained clinician using a four-point Likert scale, regarding the severity of fear and avoidance experienced by the patient over the previous week. The point total was obtained by adding scores from the fear and avoidance items. The reliability and validity study of the Turkish version of the LSAS was performed by Soykan et al. ${ }^{10}$

\section{Hamilton Depression Rating Scale}

The Hamilton Depression Rating Scale (HAM-D) is conducted by a trained interviewer and measures the severity of depression in a patient. The HAM-D was developed by Hamilton in 1959 and consists of 17 items. ${ }^{11}$ The reliability and validity study of the Turkish version of the HAM-D was conducted by Akdemir et al. ${ }^{12}$

\section{Hoehn and Yahr Staging Scale}

The Hoehn and Yahr Staging Scale was developed by Hoehn and Yahr in 1967 and is the scale most frequently used to determine the clinical severity of PD symptoms. ${ }^{13}$ The distribution and severity of parkinsonian symptoms are described according to the progression through five stages: stage 1, unilateral disease; stage 2, bilateral disease without postural instability; stage 3, mild-moderate bilateral disease and the presence of postural instability; stage 4, severe disability, but the patient can stand or walk unaided; and stage 5 , bedridden or needs wheelchair, unless receiving help. 


\section{Schwab England Activities of Daily Living Scale}

The Schwab England Activities of Daily Living (SE ADL) scale was developed by Schwab and England in 1957 and consists of ten items intended to evaluate the daily life activities of a patient. ${ }^{14}$ The SE ADL is composed of two sections: the first is a self-report questionnaire in which patients grade their own daily life activities, such as dressing, using the toilet, resting, eating, and social activities (subjective assessment), and the second is an assessment of motor functions, such as postural balance, speaking, rigidity, and tremors, conducted by a clinician (objective assessment). The results are reported between $0 \%$ (bedridden) and 100\% (healthy). However, because there was no descriptive guide for the original scale, the reliability of patient-reported assessments was uncertain. The reliability study of the SE ADL was performed by Akbostanci et al. ${ }^{15}$

\section{Unified Parkinson's Disease Rating Scale}

The Unified Parkinson's Disease Rating Scale (UPDRS) was developed by Fahn, Elton, and the UPDRS Development Committee members in 1987 and is the scale most commonly used to evaluate the clinical functional status of PD patients. ${ }^{16}$ The UPDRS consists of 42 items categorized into four chapters: 1) thoughts, behavior, and mood (UPDRS-I); 2) daily living activities (UPDRS-II); 3 ) motor examination (UPDRS-III); and 4) treatment complications, including dyskinesia, motor fluctuations, and others (UPDRS-IV A, $\mathrm{B}, \mathrm{C})$. The reliability and validity study of the UPDRS was conducted by Akbostanci et al. ${ }^{17}$

\section{Procedure}

Patients with a diagnosis of PD who presented as outpatients to the Parkinson's Disease and Movement Disorders Clinic were evaluated by a single psychiatrist following an evaluation by a single neurologist who specializes in PD. Social phobia was diagnosed by the psychiatrist, using the SCID-I.

\section{Statistical analysis}

All research data were analyzed using SPSS version 15.0 (SPSS, Inc.; Chicago, IL, USA). A Student's $t$-test or a MannWhitney $U$ test was used to compare the quantitative data, and a chi-square or Fisher's exact test were used to compare categorical data. Either a Pearson or Kendall's tau-b correlation analysis was used for the correlation analysis. A logistic regression analysis was performed to investigate the relationship between bilateral dependent variables and independent variables.
All tests were two-tailed, and a significance level of $P<0.05$ was considered to be significant.

\section{Results}

Of the $80 \mathrm{PD}$ patients in this study, 34 (42.5\%) were diagnosed with social phobia. Of these, it was determined that three $(8.8 \%)$ had social phobia prior to PD but that their avoidance behaviors increased with the onset of PD. Furthermore, nine of the 34 patients (26.5\%) expressed social anxiety at a level that did not meet the diagnostic criteria for social phobia prior to $\mathrm{PD}$, but their social anxieties increased with the onset of PD and eventually reached a clinical level. Twenty-one out of 34 PD patients with social phobia were treated by selective serotonin reuptake inhibitor (SSRI) drugs. Social phobia was comorbid with depression in 20 patients $(58.8 \%)$, generalized anxiety disorder in 18 patients $(52.9 \%)$, and panic disorder in six patients $(17.6 \%)$. In addition, of the 80 subjects, 42 patients $(52.5 \%)$ were diagnosed with depression, 34 patients $(42.5 \%)$ were diagnosed with generalized anxiety disorder, six patients $(7.5 \%)$ were diagnosed with panic disorder, and four patients (5\%) were diagnosed with obsessive-compulsive disorder.

Sex was also a determinant in the development of social phobia as it was experienced more by men (Table 1). In addition, social phobia was more common in patients with an earlier age of disease onset, longer disease duration, the presence of postural instability, and high LEDD use. The SE ADL score was higher in patients who did not have social phobia (Table 2). Twenty-eight patients (35\%) experienced motor fluctuations.

A univariate analysis revealed that five independent variables had significant relationships with social phobia. Further investigation with a logistic regression analysis showed that the risk for social phobia was four times greater for men than

Table I Sociodemographic characteristics of Parkinson's disease patients with and without social phobia

\begin{tabular}{|c|c|c|c|}
\hline Variables & $\begin{array}{l}\text { With social } \\
\text { phobia } \\
\text { n (\%) }\end{array}$ & $\begin{array}{l}\text { Without } \\
\text { social phobia } \\
\text { n (\%) }\end{array}$ & $P$-value \\
\hline \multicolumn{4}{|l|}{ Sex } \\
\hline Male $(n=48)$ & $28(58.3)$ & $20(4 I .7)$ & $0.02 *$ \\
\hline Female $(n=32)$ & $6(18.7)$ & $26(81.3)$ & \\
\hline Education $(y r)($ mean $\pm S D)$ & $7.8 \pm 3.5$ & $9.4 \pm 3.7$ & $0.07 * *$ \\
\hline Age $(y r)($ mean $\pm S D)$ & $61.4 \pm 8.2$ & $63.2 \pm 7.7$ & $0.31 * *$ \\
\hline \multicolumn{4}{|l|}{ Marital status } \\
\hline Married $(n=68)$ & $30(44.1)$ & 38 (55.9) & $0.49 * * *$ \\
\hline Unmarried $(n=12)$ & $4(33.3)$ & $8(66.7)$ & \\
\hline
\end{tabular}

Notes: *Chi-square test; **Student's $t$-test; ${ }^{* * *}$ Fisher's exact test. Abbreviation: SD, standard deviation. 
Table 2 Clinical features of Parkinson's disease patients with and without social phobia

\begin{tabular}{|c|c|c|c|}
\hline Variables & $\begin{array}{l}\text { With } \\
\text { social } \\
\text { phobia }\end{array}$ & $\begin{array}{l}\text { Without } \\
\text { social } \\
\text { phobia }\end{array}$ & $P$-value \\
\hline $\begin{array}{l}\text { Age of disease onset (yr) } \\
\text { (mean } \pm \text { SD) }\end{array}$ & $52.5 \pm 8.5$ & $57.1 \pm 9.8$ & $0.02 *$ \\
\hline $\begin{array}{l}\text { Disease duration (yr) } \\
(\text { mean } \pm S D)\end{array}$ & $8.4 \pm 5.1$ & $5.8 \pm 4.5$ & $0.02 *$ \\
\hline \multicolumn{4}{|l|}{ Predominant clinical phenotype } \\
\hline Tremor $(n=42)$ & $16(38.1)$ & $26(61.9)$ & $0.4 I^{* *}$ \\
\hline Bradykinesia $(n=38)$ & $18(47.4)$ & $20(52.6)$ & \\
\hline \multicolumn{4}{|l|}{ Lateralization } \\
\hline Right $(n=50)$ & $22(44.0)$ & $28(56.0)$ & $0.73 * *$ \\
\hline Left $(n=30)$ & $12(40.0)$ & $18(60.0)$ & \\
\hline \multicolumn{4}{|c|}{ Presence of postural instability } \\
\hline Absence $(n=24)$ & $4(16.7)$ & $20(83.3)$ & $0.003^{* *}$ \\
\hline Mild $(n=20)$ & $8(40.0)$ & $12(60.0)$ & \\
\hline Moderate-severe $(n=36)$ & $22(61.1)$ & $14(38.9)$ & \\
\hline LEDD $(\mathrm{mg} / \mathrm{d})($ mean $\pm \mathrm{SD})$ & $835.2 \pm 608.4$ & $582.2 \pm 361.7$ & $0.036^{*}$ \\
\hline UPDRS total score (mean \pm SD & $23.2 \pm 10.4$ & $17.7 \pm 15.2$ & $0.075^{*}$ \\
\hline SE ADL score (mean $\pm \mathrm{SD})$ & $77.6 \pm 9.5$ & $82.6 \pm 9.9$ & $0.028 *$ \\
\hline HAM-D score (mean \pm SD) & $17.5 \pm 6.2$ & $16.3 \pm 5.8$ & $0.726^{*}$ \\
\hline
\end{tabular}

Notes: *Student $t$-test; **chi-square test.

Abbreviations: HAM-D, Hamilton Depression Rating Scale; LEDD, levodopa equivalent daily dose; SD, standard deviation; SE ADL, Schwab England activities of daily living; UPDRS, Unified Parkinson's Disease Rating Scale; yr, year.

women, 6.5 times greater for patients with the presence of severe postural instability, and 2.1 times greater for patients with mild postural instability (Table 3 ). The LSAS score had a moderately significant inverse correlation with the age of disease onset $(r=-0.503 ; P=0.002)$ and a moderately positive relationship with disease duration $(r=0.374 ; P=0.023)$ (Table 4).

\section{Discussion}

We investigated the relationship between the frequency of social phobia in PD patients and the clinical variables

Table 3 Independent demographic and clinical predictors of social phobia in multiple logistic regression analysis

\begin{tabular}{|c|c|c|c|}
\hline Variables & Odds ratio & $95 \% \mathrm{CI}$ & $P$-value \\
\hline \multicolumn{4}{|l|}{ Sex } \\
\hline Male & 4.069 & $1.243-13.316$ & 0.020 \\
\hline \multicolumn{4}{|l|}{ Female* } \\
\hline Disease duration & 0.897 & $0.74 I-1.086$ & 0.265 \\
\hline Age of disease onset & 0.955 & $0.892-1.023$ & 0.187 \\
\hline \multicolumn{4}{|c|}{ Presence of postural instability } \\
\hline Mild & 2.111 & I.459-9.706 & 0.033 \\
\hline Moderate-severe & 6.477 & $1.305-32.158$ & 0.022 \\
\hline \multicolumn{4}{|c|}{ Absence of postural instability* } \\
\hline LEDD (mg/d) & 1.001 & $1.000-1.003$ & 0.162 \\
\hline
\end{tabular}

Note: *Reference.

Abbreviations: $\mathrm{Cl}$, confidence interval; LEDD, levodopa equivalent daily dose.
Table 4 Bivariate correlation analysis between Liebowitz Social Anxiety Scale Score with disease duration, age of disease onset, severity and functional status of disease, and depression

\begin{tabular}{lll}
\hline Variables & \multicolumn{2}{l}{ Liebowitz Social Anxiety Scale } \\
\cline { 2 - 3 } & $\boldsymbol{r}$ & $\boldsymbol{P}$-value \\
\hline Age of disease onset & -0.503 & $0.002^{*}$ \\
Disease duration & 0.374 & $0.023^{*}$ \\
HY score & 0.241 & $0.15 \mathrm{I}^{* *}$ \\
UPDRS total score & 0.208 & $0.218^{*}$ \\
SE ADL & -0.266 & 0.111 \\
HAM-D & 0.057 & 0.736 \\
\hline
\end{tabular}

Notes: *Pearson correlation analysis; **Kendall's tau-b correlation analysis.

Abbreviations: HAM-D, Hamilton Depression Rating Scale; HY, Hoehn and Yahr Staging Scale; SE ADL, Schwab England activities of daily living; UPDRS, Unified Parkinson's Disease Rating Scale.

associated with PD. Of the 80 PD patients evaluated in the present study, 34 (42.5\%) were diagnosed with social phobia. Three patients had a diagnosis of social phobia prior to their PD, although the severity of the symptoms and the incidence of avoidance behaviors increased with the onset of PD. Approximately one-quarter of the patients diagnosed with social phobia (26.5\%) experienced some concern in social environments prior to PD, but their social anxiety increased and reached a clinical level with the onset of PD. Thus, social phobia appears to emerge with the onset of PD in some patients and increases in incidence and severity in others. As the development of social phobia in PD patients is multifactorial, it is very hard to determine to what extent factors such as Levodopa induce neuropsychiatric symptoms, PD-related neuropsychiatric symptoms, or primary phobic anxiety disorder comorbidity contribute. It is especially hard to explain the etiology of the social phobia developing after onset of PD or social phobia reaching clinical levels.

Moreover, social phobia was comorbid with depression in 20 patients $(58.8 \%)$, generalized anxiety disorder in 18 patients $(52.9 \%)$, and panic disorder in six patients $(17.6 \%)$. Bolluk et $\mathrm{al}^{18}$ determined that the prevalence of social phobia was $16 \%$ in PD patients, that some patients did not have anxiety prior to the onset of PD, and that social anxiety was related to the nature of the PD symptoms. In the present study, major depressive disorder was observed in two of eight PD patients (25\%) with social phobia.

Kummer et a ${ }^{19}$ investigated the psychometric properties of the LSAS in relation to the frequency of social phobia in PD patients and found that social phobia was present in 45 of 90 patients (50\%). However, there were no relationships with any sociodemographic or clinical characteristics. In a study of $133 \mathrm{PD}$ patients in China, Chen et $\mathrm{a}^{20}$ found that $27.1 \%$ of 
patients had an anxiety disorder, with the most common being agoraphobia and social phobia. The independent predictors for an anxiety disorder were an earlier onset of PD, score on the elderly depression scale, and muscle cramps. Another study conducted on PD patients in Australia, by Dissanayaka et al, ${ }^{21}$ found that $25 \%$ of patients with anxiety disorders had either a panic disorder $(8 \%)$, generalized anxiety disorder $(3 \%)$, or social phobia $(13 \%)$.

The current finding that $42.5 \%$ of PD patients express social phobia is similar to the report of Kummer et al, ${ }^{19}$ although the rate observed here was higher than those found by Bolluk et al, ${ }^{18}$ Chen et al, ${ }^{20}$ and Dissanayaka et al. ${ }^{21}$ This difference may be due to variation in the evaluation of the social phobia subtypes. In the present study, the avoidance of one or more social situations, due to fear, was considered to be a social phobia, which may have caused the prevalence rate to be higher than other studies.

This study also assessed the incidence of other types of psychiatric disorders in PD patients and observed elevated rates of depression $(52.5 \%)$, generalized anxiety disorder (42.5\%), panic disorder (7.5\%), and obsessive-compulsive disorder $(5 \%)$. At least one type anxiety disorder was found in $62.5 \%$ of PD patients. However, Bolluk et al ${ }^{18}$ found that $30 \%$ of PD patients expressed major depressive disorder. de Rijk and Bij122 observed that $39.1 \%$ of PD patients had psychiatric disorders. Moreover, four of the ten PD patients reported that their first attack of depression or anxiety occurred within the first year of PD onset. Pontone et $\mathrm{al}^{23}$ specified the frequency of at least one anxiety disorder in $\mathrm{PD}$ patients to be $43 \%$, while Leentjens et $\mathrm{al}^{24}$ found the frequency to be $34 \%$. In the latter study, female sex, the presence of motor fluctuations, as well as a previous history of an anxiety disorder were markers for anxiety disorders.

Furthermore, social phobia was more frequently observed in men, patients with an earlier age of disease onset, longer disease duration, the presence of postural instability, and higher LEDD. A multivariate analysis revealed that sex (male) was an independent risk factor for postural instability during the development of social phobia. Bolluk et $\mathrm{al}^{18}$ found that the HAM-D score and age of a patient were predictors of the severity of social anxiety, and Dissanayaka et $\mathrm{al}^{21}$ determined that PD patients with postural instability and gait disorder experienced greater levels of anxiety relative to patients with a tremor and that there was a relationship between patient age and age at onset of PD. It may be that the men in the present study were more likely to have social phobia due to expectations of sex and social roles.
Both biopsychological and psychopharmacological mechanisms have been used to explain social phobia in patients with PD. The anxiety in these patients may be related to the neurochemical changes of the disease itself. Norepinephrine, serotonin, dopamine, and gamma-aminobutyric acid (GABA) have all been implicated in the pathogenesis of anxiety. ${ }^{1}$ There is no consensus on whether antiparkinsonian medications are responsible for symptoms of anxiety in PD. ${ }^{1}$ On the other hand, a review of the literature suggests that in social phobia, dopamine-mediated striatal circuits may also be important. ${ }^{25}$ We attempted to address the alternate psychosocial viewpoint in our study.

We also found an inverse correlation between the level of social anxiety and age of disease onset as well as a positive correlation between social anxiety and disease duration. However, there was no correlation between the clinical functional status of the patients and the total UPDRS score. Bolluk et al ${ }^{18}$ observed a positive correlation between levels of social anxiety and the total UPDRS score, but the correlations were between different clinical characteristics of PD. Therefore, the age of disease onset and disease duration in the current study and the severity of PD in the study of Bolluk et $\mathrm{al}^{18}$ were associated with levels of social anxiety. Because there are a limited number of studies that have investigated social phobia in PD patients, it was difficult to evaluate these different results.

In the present study, daily life activities decreased in PD patients with social phobia, relative to PD patients without social phobia. Similarly, Dissanayaka et $\mathrm{al}^{21}$ found that the quality of life in PD patients with anxiety was diminished compared with PD patients without anxiety. Anxiety has been shown to influence levels of social phobia and the quality of life in PD patients, at a significant rate. ${ }^{26,27}$ Independently, these two disorders decrease the quality of life of patients, and when these are comorbid, it can be expected that there will be a significant decrease in quality of life.

The present study had several limitations. First, all anxiety disorder patients were included in the study considering the risk of reduction of the sample size and for evaluating all patients with and without social phobia. Further, no control groups were included in this study. Our main purpose in this study was to determine predictors of social phobia among patients attending an outpatient clinic and diagnosed with PD during a specific period. We did not plan to form a control group as this was not planned as a prevalence study. However, we also preferred to report the frequency we found during our study.

In conclusion, the fact that $42.5 \%$ of PD patients in the present study were diagnosed with social phobia, 
underscores the magnitude and importance of this issue. Moreover, $57.5 \%$ of patients with PD had similar complaints, even if not at a clinical level, and this demonstrates that social phobia does not necessarily develop in all PD patients and that social phobia requires a separate diagnosis. The early assessment, recognition, and treatment of social phobia and other psychiatric disorders in PD patients can help effect positive changes in the quality of life of these patients and their caregivers.

\section{Disclosure}

The authors report no conflicts of interest in this work.

\section{References}

1. Walsh K, Bennett G. Parkinson's disease and anxiety. Postgrad Med J. 2001;77(904):89-93.

2. Tunc T, Emre U, Coskun O, Okuyucu E, Vargel SY, Inan LE. [Anxiety Disorder in Parkinson's Disease]. Parkinson Hast Hareket Boz Der. 2007;10:22-25. Turkish.

3. American Psychiatric Association. Diagnostic and Statistical Manual of Mental Disorders, Fourth Edition - DSM-IV. Washington, DC: American Psychiatric Association; 1994.

4. Topçuoğlu V, Bez Y, Sahin Biçer D, et al. [Social phobia in essential tremor]. Turk Psikiyatri Derg. 2006;17(2):93-100. Turkish.

5. Stein MB, Baird A, Walker JR. Social phobia in adults with stuttering. Am J Psychiatry. 1996;153:278-280.

6. Gündel H, Wolf A, Xidara V, Busch R, Ceballos-Baumann AO. Social phobia in spasmodic torticollis. J Neurol Neurosurg Psychiatry. 2001;71(4):499-504.

7. First MB, Spitzer RL, Gibbon M, Williams JBW. Structured Clinical Interview for DSM-IV Axis 1 Disorders, Clinical Version (SCID-CV). Washington, DC: American Psychiatric Press; 1997.

8. Ozkurkcugil A, Aydemir O, Yıldız M, Danacı AE, Koroglu E. DSM-IV Eksen I Bozuklukları İçin Yapılandırılmış Klinik Görüşmenin Türkçe'ye Uyarlanması ve Güvenilirlik Çalışması. [DSM-IV Structured Clinical Interview for Axis I Disorders; the Turkish Adaptation and Reliability study]. İlaç ve Tedavi Dergisi. 1999;12:233-236. Turkish.

9. Liebowitz MR. Social phobia. Mod Probl Pharmacopsychiatry. 1987;22:141-173.

10. Soykan C, Ozgüven HD, Gençöz T. Liebowitz Social Anxiety Scale: the Turkish version. Psychol Rep. 2003;93(3 Pt 2):1059-1069.

11. Hamilton M. The assesment of anxiety states by rating. $\mathrm{Br} J \mathrm{Med}$ Psychol. 1959;32(1):50-55.
12. Akdemir A, Türkçapar MH, Orsel SD, Demirergi N, Dag I, Ozbay MH. Reliability and validity of the Turkish version of the Hamilton Depression Rating Scale. Compr Psychiatry. 2001;42(2):161-165.

13. Hoehn MM, Yahr MD. Parkinsonism: onset, progression and mortality. Neurology. 1967;17(5):427-442.

14. Schwab RS, England AC. Newer preparations in the treatment of Parkinsonism. Med Clin North Am. 1957;41(2):369-379.

15. Akbostanci MC, Kocatürk PA, Tan FU, Kavas GO. Erythrocyte superoxide dismutase activity differs in clinical subgroups of Parkinson's disease patients. Acta Neurol Belg. 2001;101(3):180-183.

16. Fahn S, Elton RL, the UPDRS Development Committee: Unified Parkinson's Disease Rating Scale. In: Fahn S, Marsden CD, Calne D, Goldstein M, editors. Recent Developments in Parkinson's Disease. Florham Park, NJ: Macmillan; 1987:153-163.

17. Akbostanci MC, Balaban $\mathrm{H}$, Atbasoglu C. [Interrater reliability study of motor examination subscale of UPDRS and AIMS]. Parkinson Hast Hareket Boz Der. 2000;3:7-13. Turkish.

18. Bolluk B, Ozel-Kizil ET, Akbostanci MC, Atbasoglu EC. Social anxiety in patients with Parkinson's disease. J Neuropsychiatry Clin Neurosci. 2010;22(4):390-394.

19. Kummer A, Cardoso F, Teixeira AL. Frequency of social phobia and psychometric properties of the Liebowitz social anxiety scale in Parkinson's disease. Mov Disord. 2008;23(12):1739-1743.

20. Chen YK, Lu JY, Chan DM, et al. Anxiety disorders in Chinese patients with Parkinson's disease. Int J Psychiatry Med. 2010;40(1):97-107.

21. Dissanayaka NN, Sellbach A, Matheson S, et al. Anxiety disorders in Parkinson's disease: prevalence and risk factors. Mov Disord. 2010;25(7):838-845.

22. de Rijk C, Bijl RV. [Prevalence of mental disorders in persons with Parkinson's disease]. Ned Tijdschr Geneeskd. 1998;142(1):27-31. Dutch.

23. Pontone GM, Williams JR, Anderson KE, et al. Prevalence of anxiety disorders and anxiety subtypes in patients with Parkinson's disease. Mov Disord. 2009;24(9):1333-1338.

24. Leentjens AF, Dujardin K, Marsh L, Martinez-Martin P, Richard IH, Starkstein SE. Symptomatology and markers of anxiety disorders in Parkinson's disease: a cross-sectional study. Mov Disord. 2011;26(3): 484-492.

25. Stein DJ, Westenberg HG, Liebowitz MR. Social anxiety disorder and generalized anxiety disorder: serotonergic and dopaminergic neurocircuitry. J Clin Psychiatry. 2002;63 Suppl 6:S12-S19.

26. Stein MB, Kean YM. Disability and quality of life in social phobia: epidemiologic findings. Am J Psychiatry. 2000;157(10):1606-1613.

27. Ozdilek B, Gunal DI. Motor and non-motor symptoms in Turkish patients with Parkinson's disease affecting family caregiver burden and quality of life. J Neuropsychiatry Clin Neurosci. 2012;24(4):478-483.
Neuropsychiatric Disease and Treatment

\section{Publish your work in this journal}

Neuropsychiatric Disease and Treatment is an international, peerreviewed journal of clinical therapeutics and pharmacology focusing on concise rapid reporting of clinical or pre-clinical studies on a range of neuropsychiatric and neurological disorders. This journal is indexed on PubMed Central, the 'PsycINFO' database and CAS.
Dovepress

The manuscript management system is completely online and includes a very quick and fair peer-review system, which is all easy to use. Visit http://www.dovepress.com/testimonials.php to read real quotes from published authors. 